\title{
A Two-phase Reaction System for Selective Oxidative Degradation of Lignin Model Compounds
}

Yueying Chen, Aiguo Xue, Haomin Jiang, Yujuan Cheng, Yuan Ren, Yanzhi Sun, and Yongmei Chen *

Lignin depolymerization through an oxidation method could provide valueadded products, but it is challenging in terms of recovering catalysts or separating products in time to avoid over-oxidation. In this study, a process of selectively oxidative degradation of lignin model compounds was operated in a two-phase reaction system. Lignin model compounds of 4benzyloxyphenol (PBP) or guaiacylglycerol- $\beta$-guaiacyl ether (GGE) in a bottom phase of 1-butyl-3-methylimidazole chloride ([BMIM]Cl) ionic liquid were selectively oxidized by $\mathrm{H}_{2} \mathrm{O}_{2}$ in the presence of a solid acid $\left(\mathrm{SO}_{4}{ }^{2-}\right.$ $/ \mathrm{Fe}_{2} \mathrm{O}_{3}-\mathrm{ZrO}_{2}$ ), and the degradation products immediately diffused into the upper organic solvent phase (butyl acetate). In this kind of reaction system, the yield of the products was improved due to the prolonged life of $\cdot \mathrm{OH}$ in ionic liquid, and the product selectivity was maintained due to the timely product separation, and the ionic liquid and the catalyst were easily recycled.

Keywords: Lignin model compound; Products selectivity; Ionic liquid; Solid acid

Contact information: Institute of Applied Electrochemistry, College of Chemistry, Beijing University of Chemical Technology, No.15 North Third Ring Road, Chaoyang District, Beijing 100029, China;

* Corresponding author: chenym@mail.buct.edu.cn

\section{INTRODUCTION}

Lignin makes up a significant portion of the mass of dry wood and, after cellulose, it is the second most abundant form of organic carbon in the biosphere. Lignin is also regarded as a unique renewable aromatic resource in nature (Amidon and Liu 2009), because it is composed of a large number of phenylpropyl (C9) units, such as guaiacyl, syringyl, or p-hydroxypropyl units and the propyl side-chains. Since these units are randomly linked with each other by the $\mathrm{C}-\mathrm{O}-\mathrm{C}$ bonds (such as $\alpha-\mathrm{O}-4, \beta-\mathrm{O}-4$, and $4-\mathrm{O}-5$ ) or $\mathrm{C}-\mathrm{C}$ bonds (such as 5-5, $\beta-5$, and $\beta-\beta$ ) (Xu et al. 2014) and the linkage bonds are usually weak, the small-weight aromatic compounds could be obtained if these linkage bonds could be selectively cleaved by chemical methods. These selective depolymerization methods are the important ways of lignin valorization ( $\mathrm{Li}$ and Song 2019).

Several chemical methods, such as pyrolysis (Yang et al. 2010; Persson et al. 2018), hydrolysis (Tarabanko et al. 2000; Yuan et al. 2010; Li et al. 2015), and hydrogenolysis (Xu et al. 2012; Song et al. 2013) are used to depolymerize lignin, and the researchers are trying to optimize the operation conditions under mild temperature and pressure with more selective productions. The cleavage of an aryl-alkyl ether bond occurs, catalyzed by a Lewis acid (Deepa and Dhepe 2015; Wang et al. 2018; Guan et al. 2020). Lignin or lignin model compounds could be depolymerized by $\mathrm{H}_{2} \mathrm{O}_{2}$ oxidative degradation, in which the generated reactive oxygen species (ROS) act as oxidizing reagent (Kang et al. 2019). Certain products are generated by selective cleavage of linkage bonds (Lei et al. 2017; 
Jiang et al. 2019). However, the product selectivity is reduced if a liquor having strong acidity (such as $\mathrm{H}_{2} \mathrm{SO}_{4}$ ) is used as the co-catalyst because over-oxidation of the products can occur, making product separation difficult.

Reactive oxygen species are stabilized in ionic liquids (ILs) because the large ion volume, steric hindrance, and solvation effect of ILs can slow the self-quenching process of radicals (Zigah et al. 2009). Some ILs, for example ILs with imidazolium cations, possess good dissolvability for lignin or lignin model compounds because of the strong $\pi$ $\pi$ conjugation between their aromatic cations and the benzene rings in lignin molecules (Prado et al. 2016). If the depolymerized products could be separated immediately from the reaction system, ILs could be an ideal solvent for lignin depolymerization by oxidation. Otherwise, parts of phenol groups in the degraded products might be over-oxidized to aldehyde or carboxylic groups.

To avoid the over-oxidization of the depolymerization, an IL ([BMIM]Cl) and an organic solvent (butyl acetate), which are undissolved with each other, were chosen to compose a two-phase reaction system in this study. 4-Benzyloxyphenol (PBP) and guaiacylglycerol- $\beta$-guaiacyl ether (GGE) (Fig. 1) as lignin model compounds were dissolved in IL, and they were supposed to react with the ROS generated through the decomposition of $\mathrm{H}_{2} \mathrm{O}_{2}$ catalyzed by a solid acid $\left(\mathrm{SO}_{4}{ }^{2-} / \mathrm{Fe}_{2} \mathrm{O}_{3}-\mathrm{ZrO}_{2}\right)$, while the degraded products (compounds with single benzene ring) might transfer into the organic solvent due to the distribution coefficient. The cleavage mechanism of linkage bonds was considered in this study based on the products analysis and degradation rates.

(a)

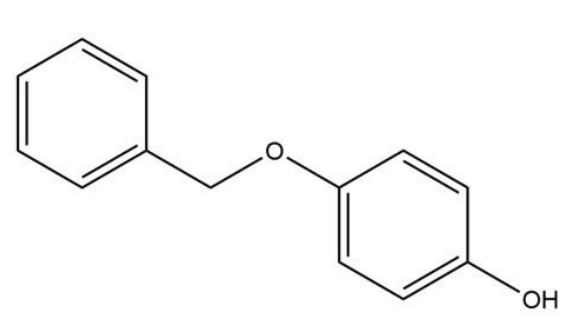

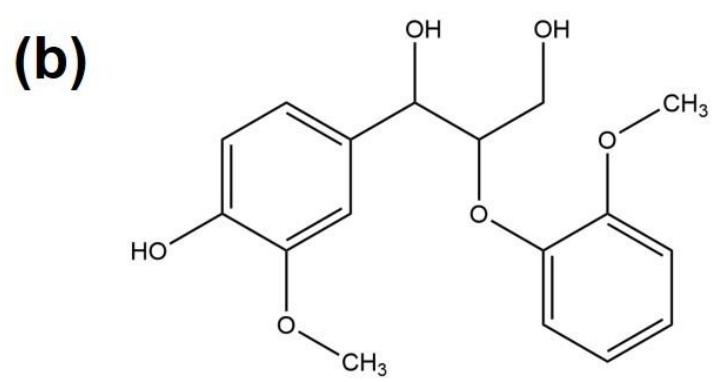

Fig. 1. Molecular structures of (a) 4-benzyloxyphenol (PBP); (b) guaiacylglycerol- $\beta$-guaiacyl ether (GGE)

\section{EXPERIMENTAL}

\section{Materials}

Sulfuric acid, hydrogen peroxide $(30 \%)$, potassium permanganate, iron nitrate nonahydrate, and ammonium hydroxide were purchased from Beijing Chemical Reagents Company (Beijing, China). Sodium oxalate was obtained from Guangfu Technology Development Limited Company (Tianjin, China). Zirconium oxychloride octahydrate was supplied by Jinke Chemical Research Institute (Tianjin, China). Methanol was purchased from Thermo Fisher (Shanghai, China), with chromatographically purity. The 4benzyloxylphenol (PBP) and guaiacylglycerol- $\beta$-guaiacyl ether (GGE) were purchased from J\&K Scientific (Beijing, China) and 1-butyl-3-methyl imidazole chloride ([BMIM]Cl) was supplied by Linzhou Branch Material Technology Co., Ltd (Linzhou, China). 


\section{Preparation of Solid Acid}

First, $4.8 \mathrm{~g}$ of $\mathrm{ZrOCl}_{2} \cdot 8 \mathrm{H}_{2} \mathrm{O}$ and $6.0 \mathrm{~g} \mathrm{Fe}\left(\mathrm{NO}_{3}\right)_{3} \cdot 9 \mathrm{H}_{2} \mathrm{O}$ were dissolved in deionized water, and ammonia (30 wt\%) was added dropwise to adjust the $\mathrm{pH}$ to 9 to 10 under vigorous stirring. The solution was stored at room temperature for $24 \mathrm{~h}$. The filter residue was washed by deionized water until no $\mathrm{Cl}^{-}$was detected. After drying at $110{ }^{\circ} \mathrm{C}$ for $12 \mathrm{~h}$, the solid was ground and sieved to obtain powder with particle size under $300 \mu \mathrm{m}$. The powder was immersed in $1.0 \mathrm{M}$ sulfuric acid for $24 \mathrm{~h}$. The filter residue was dried at 110 ${ }^{\circ} \mathrm{C}$ for $12 \mathrm{~h}$ and calcined at $650{ }^{\circ} \mathrm{C}$ for $4 \mathrm{~h}$ in a muffle furnace. After cooling to room temperature, the solid acid $\mathrm{SO}_{4}{ }^{2-} / \mathrm{Fe}_{2} \mathrm{O}_{3}-\mathrm{ZrO}_{2}$ was obtained.

\section{Characterization of Solid Acid}

The X-ray powder diffraction (XRD) patterns were tested on a diffractometer with $\mathrm{Cu} \mathrm{K \alpha}$ radiation $(40 \mathrm{kV}, 150 \mathrm{~mA})$ and of wavelength $1.5406 \AA$ (D-8 Advanced, Bruker, Karlsruhe, Germany). X-ray photoelectron spectroscopy (XPS) measurements were performed by an X-ray photoelectron spectrometer using Al as the exciting source (Escalab 250Xi, Thermo Fisher). The acidity of the solid acid was tested by a pyridine-thermal desorption-infrared (Py-IR) spectrograph, using a Fourier transform infrared spectrometer (Nicolet Is50, Thermo Fisher).

\section{Degradation of Lignin Model Compounds}

A total of $10.0 \mathrm{mg}$ PBP was dissolved in $10.0 \mathrm{~mL}$ of [BMIM]Cl solution containing 15 wt.\% water, which was used as the stock solution. Next, $1.0 \mathrm{~mL}$ of stock solution was pipetted for each degradation experiment, in which 2.0 to $10.0 \mathrm{mg}$ of solid acid and 0.16 to $0.80 \mathrm{~mol} / \mathrm{L}$ hydrogen peroxide were added. The degradation reactions were kept at different temperatures in a water bath under stirring for $2 \mathrm{~h}$. GGE was degraded as the same process as described above.

\section{Evaluation of Degradation Rate and Products Selectivity}

For evaluating the degradation rate, $100 \mu \mathrm{L}$ of the reaction solution was sampled before and after the degradation reaction. The amount of PBP or GGE before and after degradation were determined by a high-performance liquid chromatography (HPLC, Thermo Fisher Ultimate 3000) based on standard curve method with the linear regression coefficient of 0.9992. The degradation rate (DR) is shown as Eq. 1,

$\mathrm{DR}(\%)=V / V_{0} \times 100 \%$

where $V_{0}$ and $V(\mathrm{mAU} \cdot \mathrm{min})$ are the peak areas of lignin model compounds before and after degradation, respectively.

Since the signals of the degradation products are covered by the signal of IL, the relative amounts of the degradation products in the reaction solution were determined by GC-MS after the extracted by organic solvent. The reaction solution after degradation was extracted twice with butyl acetate, and the butyl acetate phase was combined together. The compounds in it were identified by a gas chromatography-mass spectrometer (GC-MS, Shimadzu QP 2010 Ultra, Tokyo, Japan). The operation details of both HPLC and GC-MS are described in the Supplementary Information. 


\section{RESULTS AND DISCUSSION}

\section{Structure and Acidity Characterization of the Solid Acid}

The XRD patterns of the prepared solid acid $\mathrm{SO}_{4}{ }^{2-} / \mathrm{Fe}_{2} \mathrm{O}_{3}-\mathrm{ZrO}_{2}$ (Fig. 2a) disclosed that $\mathrm{SO}_{4}{ }^{2-} / \mathrm{Fe}_{2} \mathrm{O}_{3}-\mathrm{ZrO}_{2}$ is amorphous, while $\mathrm{ZrO}_{2}$ and $\mathrm{SO}_{4}{ }^{2-} / \mathrm{ZrO}_{2}$ prepared through the same process displayed perfect crystallinity. The phenomenon indicated that there were defect sites introduced in $\mathrm{SO}_{4}{ }^{2-} / \mathrm{Fe}_{2} \mathrm{O}_{3}-\mathrm{ZrO}_{2}$ by doping of $\mathrm{Fe}$.

(a)

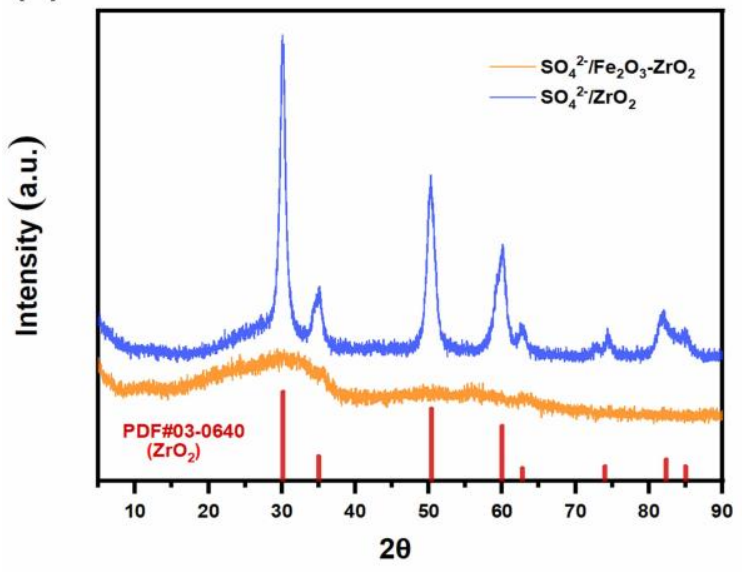

(c)

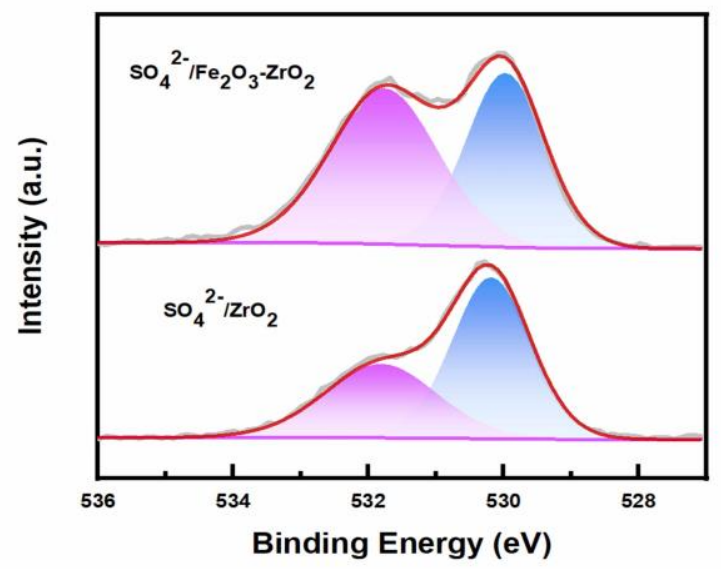

(b)

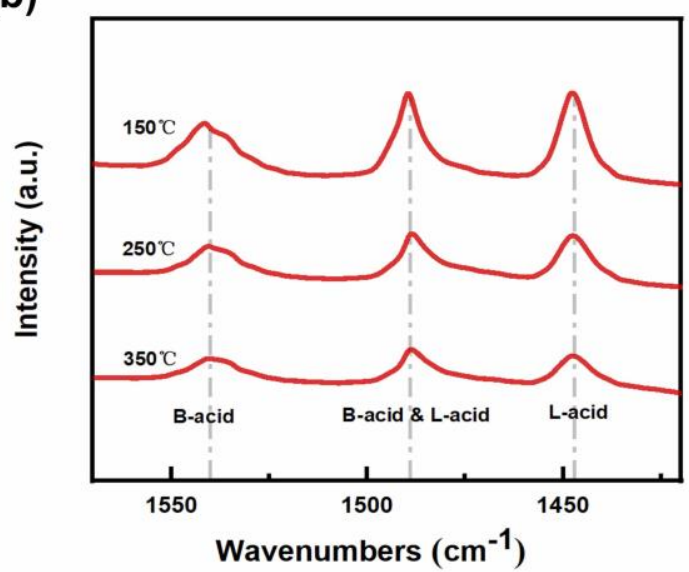

(d)

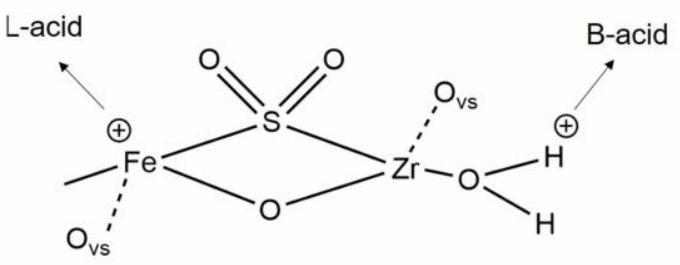

Fig. 2. (a) XRD patterns of $\mathrm{ZrO}_{2}, \mathrm{SO}_{4}{ }^{2-} / \mathrm{ZrO} 2$ and $\mathrm{SO}_{4}{ }^{2-} / \mathrm{Fe}_{2} \mathrm{O}_{3}-\mathrm{ZrO}_{2}$; (b) Py-IR spectra of $\mathrm{SO}_{4}{ }^{2-}$ $/ \mathrm{Fe}_{2} \mathrm{O}_{3}-\mathrm{ZrO}_{2}$ at $150{ }^{\circ} \mathrm{C}, 250{ }^{\circ} \mathrm{C}$, and $350{ }^{\circ} \mathrm{C} ;$ (c) O1s XPS spectra of $\mathrm{SO}_{4}{ }^{2-} / \mathrm{ZrO}_{2}$ and $\mathrm{SO}_{4}{ }^{2-} / \mathrm{Fe}_{2} \mathrm{O}_{3}-$ $\mathrm{ZrO}_{2}$; (d) diagram of $\mathrm{L}$-acid and $\mathrm{B}$-acid sites formed in $\mathrm{SO}_{4}{ }^{2-} / \mathrm{Fe}_{2} \mathrm{O}_{3}-\mathrm{ZrO}_{2}$

The Py-IR spectra of $\mathrm{SO}_{4}{ }^{2-} / \mathrm{Fe}_{2} \mathrm{O}_{3}-\mathrm{ZrO}_{2}$ at different temperatures is shown in Fig. 2b. According to Yue et al. (2019), the peak at $1445 \mathrm{~cm}^{-1}$ was assigned to the pyridine molecule adsorbed on the Lewis acid (L-acid) site of the solid acid, while the peak at 1540 $\mathrm{cm}^{-1}$ originated from the Brønsted acid (B-acid) site, and the peak at $1490 \mathrm{~cm}^{-1}$ was caused by both L-acid and B-acid sites. Although the intensity of these peaks decreased as the temperature increased, it is still obvious at $350{ }^{\circ} \mathrm{C}$, meaning these $\mathrm{L}$-acid and $\mathrm{B}$-acid sites are strong enough. 
The relative content of the oxygen vacancies was determined by XPS spectra shown in Fig. 2c. The O1s peaks in the spectra disclose two kinds of $\mathrm{O}$ atoms with different chemical atmosphere existed in the sample. The peaks at 530.01 and $531.68 \mathrm{eV}$ are assigned to the oxygen atoms in lattice and the oxygen atoms in suspending hydroxyl groups, respectively (Ismail et al. 2019), and the peak originated from oxygen atoms in adsorbed $\mathrm{SO}_{4}{ }^{2-}$ might be too weak to be detected. The relative content of lattice oxygen in $\mathrm{SO}_{4}{ }^{2-} / \mathrm{Fe}_{2} \mathrm{O}_{3}-\mathrm{ZrO}_{2}$ was $48.5 \%$, while in $\mathrm{SO}_{4}{ }^{2-} / \mathrm{ZrO}_{2}$ was $73.7 \%$. The less lattice oxygen implied there were more oxygen vacancies introduced in $\mathrm{SO}_{4}{ }^{2-} / \mathrm{Fe}_{2} \mathrm{O}_{3}-\mathrm{ZrO}_{2}$.

The schematic diagram of the acidic sites formed on $\mathrm{SO}_{4}{ }^{2-} / \mathrm{Fe}_{2} \mathrm{O}_{3}-\mathrm{ZrO}_{2}$ is shown in Fig. $2 \mathrm{~d}$. The oxygen vacancies $\left(\mathrm{O}_{\mathrm{vs}}\right)$ caused by the defects in lattice lead to the formation of $\mathrm{L}$-acid sites on $\mathrm{SO}_{4}{ }^{2-} / \mathrm{Fe}_{2} \mathrm{O}_{3}-\mathrm{ZrO}_{2}$, and the suspending $-\mathrm{OH}$ groups on the surface of the solid are related to the $\mathrm{B}$-acid sites.

\section{$\mathrm{H}_{2} \mathrm{O}_{2}$ Decomposition Catalyzed by Solid Acid}

The bromocresol green (BG) method was used to confirm the kind of ROS generated from $\mathrm{H}_{2} \mathrm{O}_{2}$ decomposition catalyzed by solid acids. The detailed experimental section is described in the Supplementary Information in the Appendix. The results showed that the absorption intensity of $\mathrm{BG}$ solution decreased in the presence of $\mathrm{H}_{2} \mathrm{O}_{2}$ and the solid acid, but the absorption intensity was almost unchanged if only $\mathrm{H}_{2} \mathrm{O}_{2}$ or solid acid were present. As an extremely stable molecule, BG is reported to be only degraded by hydroxyl radicals $(\cdot \mathrm{OH})$ attacking the electronegative $-\mathrm{Br}$ group followed by degradation (Fassi et al. 2014). The results confirmed that hydroxyl radical $(\cdot \mathrm{OH})$ was generated through $\mathrm{H}_{2} \mathrm{O}_{2}$ decomposition catalyzed by the solid acids. Thus, the oxygen vacancies in the solid acids promoted the amounts of $\cdot \mathrm{OH}$ generated by decomposition of $\mathrm{H}_{2} \mathrm{O}_{2}(\mathrm{Li}$ et al. 2017), while $\mathrm{ZrO}_{2}$ itself demonstrates a positive effect on Fenton-like reaction (Gao et al. 2019).

\section{Optimization of Degradation Conditions}

Based on the degradation rate of PBP, the operating conditions were screened. The results showed that ionic liquid as the solvent was more favorable than methanol or acetonitrile due to the stabilization effect of ROS in IL. Very little PBP was degraded when just the solid acid was present, and only about $20 \%$ degradation rate could be achieved only with $\mathrm{H}_{2} \mathrm{O}_{2}$. Over $70 \%$ PBP was degraded when both of $\mathrm{H}_{2} \mathrm{O}_{2}$ and solid acid were present. It seems to be necessary to set up the reaction system using IL as the solvent with presence of $\mathrm{H}_{2} \mathrm{O}_{2}$ and solid acid.

The parameters of reaction conditions, such as catalyst dosage, $\mathrm{H}_{2} \mathrm{O}_{2}$ concentration, reaction time, and temperature on the degradation efficiency were systemically studied. The results are shown in Fig. 3. As shown in Fig. 3a, the degradation rate (DR) increased from $20.4 \%$ to $38.5 \%$ when $2.0 \mathrm{mg}$ solid acid was added in $2 \mathrm{~h}$, and the DR increased gradually up to $73.7 \%$ as the amount of catalyst was increased to $10.0 \mathrm{mg}$. More PBP were degraded as the $\mathrm{H}_{2} \mathrm{O}_{2}$ concentration increased (Fig. 3b), and over $90 \%$ PBP was degraded when $0.32 \mathrm{~mol} / \mathrm{L} \mathrm{H}_{2} \mathrm{O}_{2}$ was used. The remaining amount of PBP was decreased as the reaction time increased.

As shown in Fig. 3c, the degradation rate was about $57.8 \%$ in 0.5 h, and $94.3 \%$ in $2 \mathrm{~h}$. When the temperature elevated, the degradation rate increased greatly (Fig. 3d). About $85.7 \%$ of PBP was degraded in $2 \mathrm{~h}$ at $60{ }^{\circ} \mathrm{C}$, while less than $5 \%$ was degraded at $20^{\circ} \mathrm{C}$ in $2 \mathrm{~h}$. 
(a)

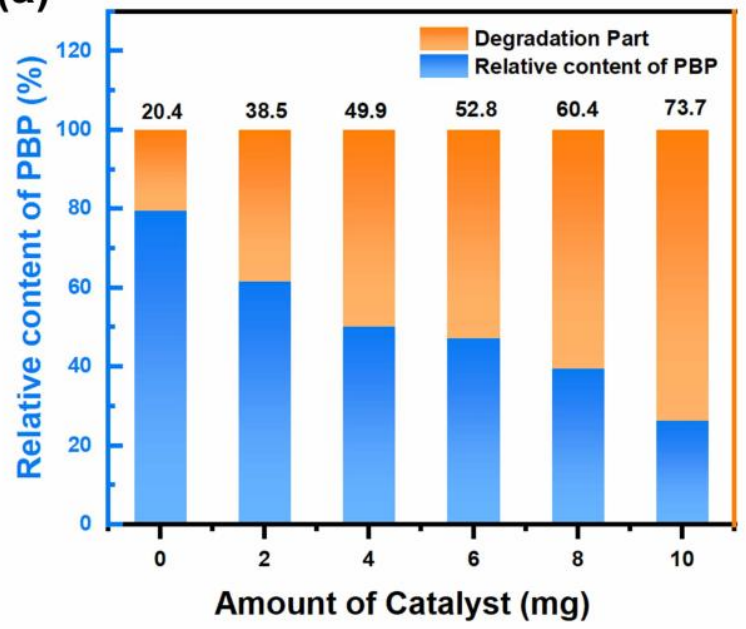

(c)

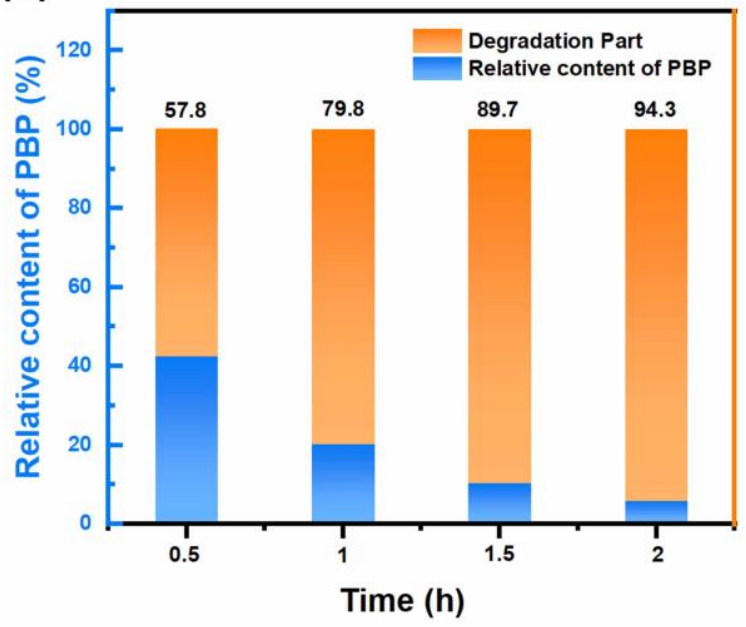

(b)

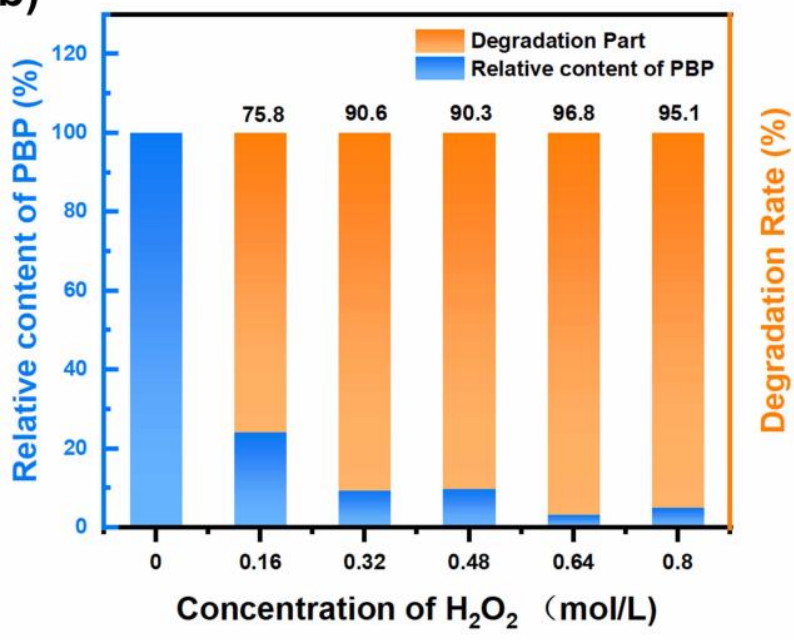

(d)

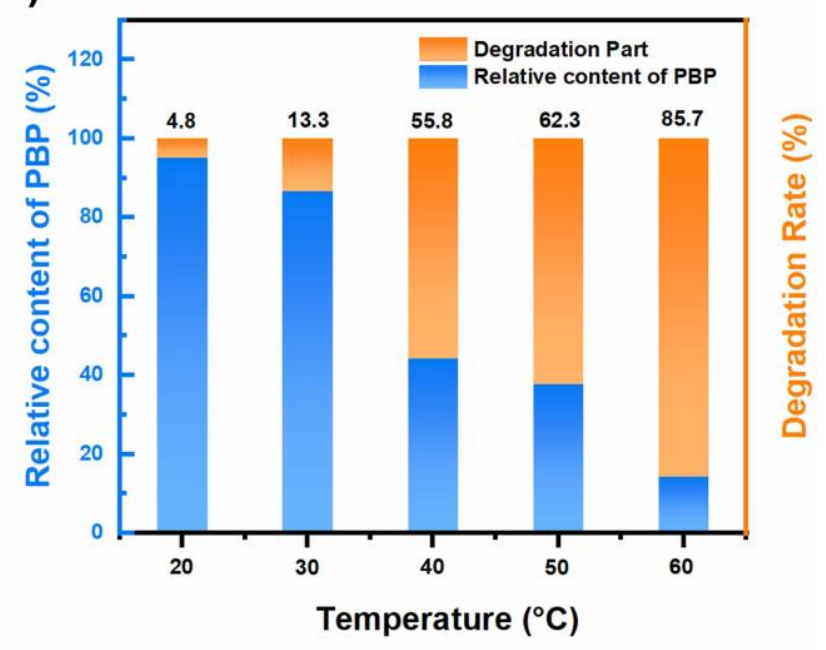

Fig. 3. The degradation rate of PBP under different operation conditions, (a) with different dosage of catalyst; (b) with different initial concentration of $\mathrm{H}_{2} \mathrm{O}_{2}$; (c) as the reaction time under the initial $\mathrm{H}_{2} \mathrm{O}_{2}$ concentration of $0.80 \mathrm{~mol} / \mathrm{L} ;(\mathrm{d})$ at different temperature. The other operation conditions were the same as follows if not mentioned: the solid acid was $\mathrm{SO}_{4}{ }^{2}-/ \mathrm{Fe}_{2} \mathrm{O}_{3}-\mathrm{ZrO}_{2}$, the initial concentration of $\mathrm{H}_{2} \mathrm{O}_{2}$ was $0.80 \mathrm{~mol} / \mathrm{L}$, catalyst dosage was $10.0 \mathrm{mg}$, the temperature was $60{ }^{\circ} \mathrm{C}$, and the duration was $2 \mathrm{~h}$.

The above phenomena indicate that the DR of PBP strongly depends on the amount of hydroxyl radicals $(\cdot \mathrm{OH})$ that are produced through catalyzed decomposition of $\mathrm{H}_{2} \mathrm{O}_{2}$. The decomposition of $\mathrm{H}_{2} \mathrm{O}_{2}$ follows the first-order kinetic reaction with reaction rate constants of $0.0121 \mathrm{~min}^{-1}$ at $20{ }^{\circ} \mathrm{C}, 0.0396 \mathrm{~min}^{-1}$ at $40{ }^{\circ} \mathrm{C}$, and $0.0965 \mathrm{~min}^{-1}$ at $60{ }^{\circ} \mathrm{C}$, respectively (Lei et al. 2017). The amount of $\cdot \mathrm{OH}$ increased when the initial concentration of $\mathrm{H}_{2} \mathrm{O}_{2}$, the dosage of catalyst, and the reaction temperature were increased.

The degradation of another lignin model compound, GGE, in this reaction system was also performed. GGE has a $\beta-\mathrm{O}-4$ bond, while PBP possesses an $\alpha-\mathrm{O}-4$ bond. As shown in Fig. 4d, 97.3\% of GGE was degraded in presence of $0.80 \mathrm{~mol} / \mathrm{L} \mathrm{H}_{2} \mathrm{O}_{2}$ and 10.0 $\mathrm{mg} \mathrm{SO}{ }_{4}^{2-} / \mathrm{Fe}_{2} \mathrm{O}_{3}-\mathrm{ZrO}_{2}$, after reacting at $60{ }^{\circ} \mathrm{C}$ for $2 \mathrm{~h}$. 
(a)

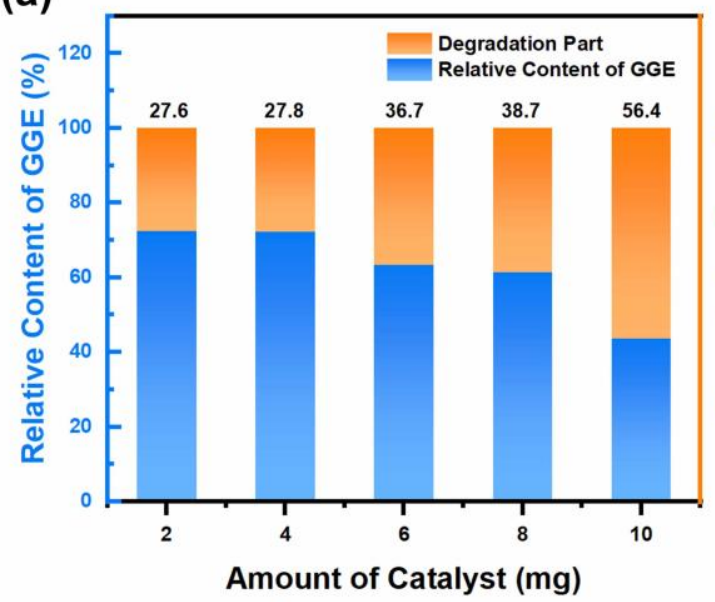

(c)

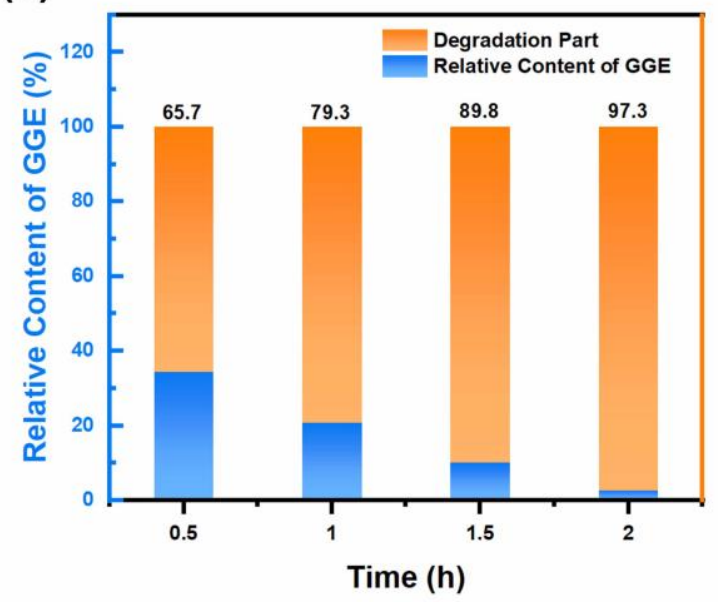

(b)

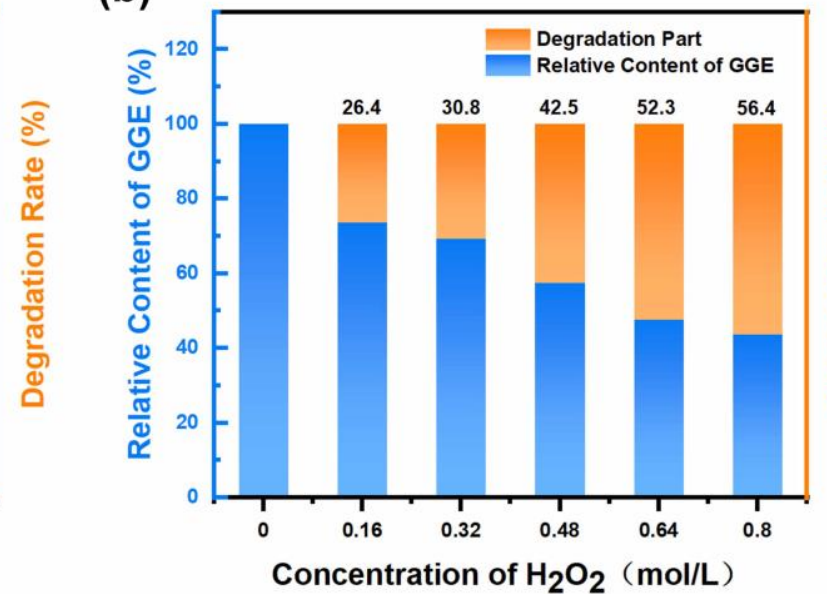

(d)

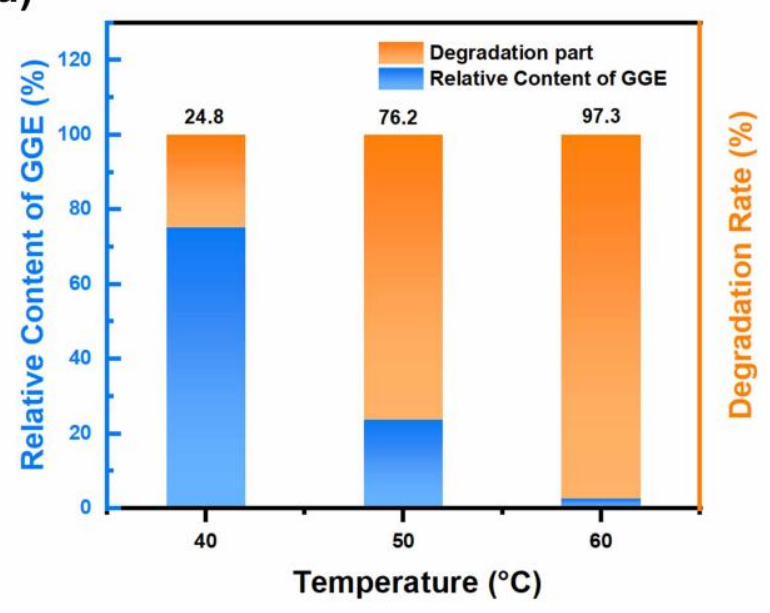

Fig. 4. The degradation rate of GGE under different operation conditions, (a) with different dosage of catalyst; (b) with different initial concentration of $\mathrm{H}_{2} \mathrm{O}_{2}$; (c) as the reaction time under the initial $\mathrm{H}_{2} \mathrm{O}_{2}$ concentration of $0.80 \mathrm{~mol} / \mathrm{L} ;(\mathrm{d})$ at different temperature. The other operation conditions were the same as follows if not mentioned: the solid acid was $\mathrm{SO}_{4}{ }^{2-} / \mathrm{Fe}_{2} \mathrm{O}_{3}-\mathrm{ZrO}_{2}$, the initial concentration of $\mathrm{H}_{2} \mathrm{O}_{2}$ was $0.80 \mathrm{~mol} / \mathrm{L}$, catalyst dosage was $10.0 \mathrm{mg}$, the temperature was $60{ }^{\circ} \mathrm{C}$, and the duration was $2 \mathrm{~h}$.

\section{Two-phase Reaction System Design}

A two-phases reaction system was designed in which the degradation products were separated immediately, taking PBP as an example. As shown in Fig. 5a, the reaction environment is composed of ionic liquid [BMIM]Cl and butyl acetate, and those are immiscible with each other. In the bottom phase of [BMIM]Cl, PBP is degraded by $\mathrm{H}_{2} \mathrm{O}_{2}$ in the presence of $\mathrm{SO}_{4}{ }^{2-} / \mathrm{Fe}_{2} \mathrm{O}_{3}-\mathrm{ZrO}_{2}$. The degraded products entered into the upper phase of butyl acetate due to solubility difference. The system was heated and stirred in a water bath. After sampling from the upper phase per hour, $\mathrm{PBP}$ and $\mathrm{H}_{2} \mathrm{O}_{2}$ were re-added.

The product yield per cycle is shown in Fig. 5b. The relative content of two main products benzyl alcohol and benzaldehyde accumulated almost linearly for five consecutive times. The amount of benzyl alcohol was much higher than that of benzaldehyde. There was no benzoic acid detected. But it's not certain that the products had been completely extracted. It was supposed there were still products dissolved in the ILs, so that the yields could not been calculated. According to the cleavage mechanism of 
PBP, benzyl alcohol is a direct product, while benzaldehyde is a secondary oxidation product. The efficiencies of degradation in the five cycles are shown in Fig. 5c, and the average value is $86.9 \%$. Using this reaction system, it is easy to control the operation conditions. The instant separation of products can be realized, and the recycling of both the ionic liquid and solid acid catalyst can be achieved.

(a)

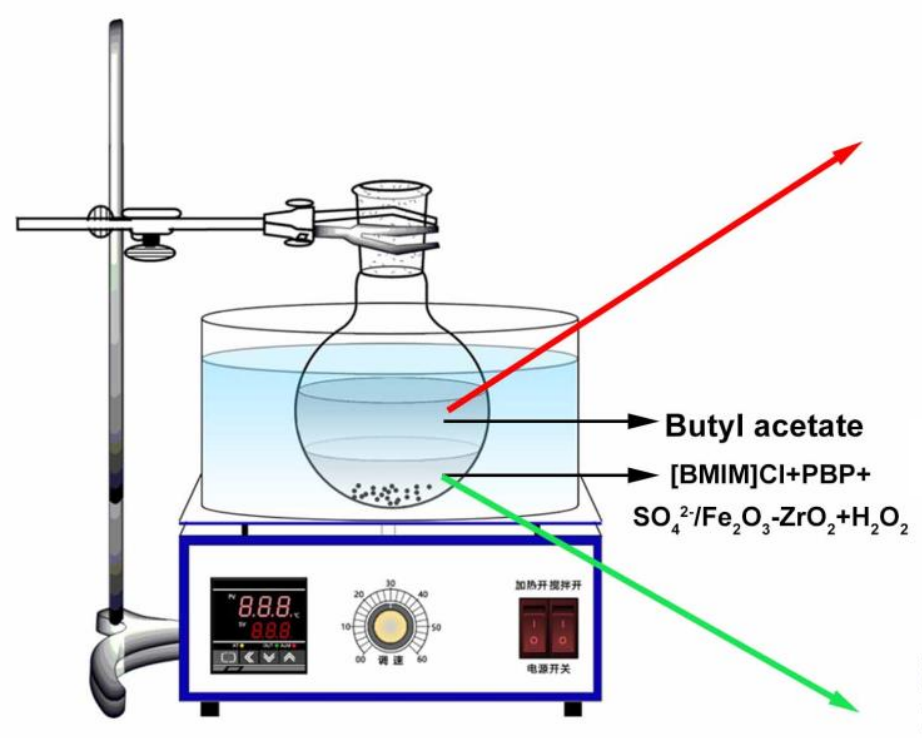

(b)

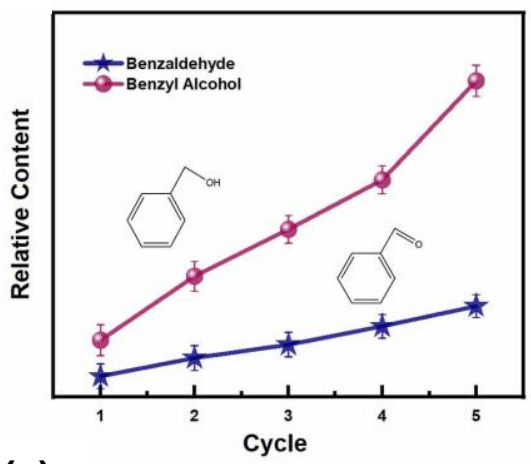

(c)

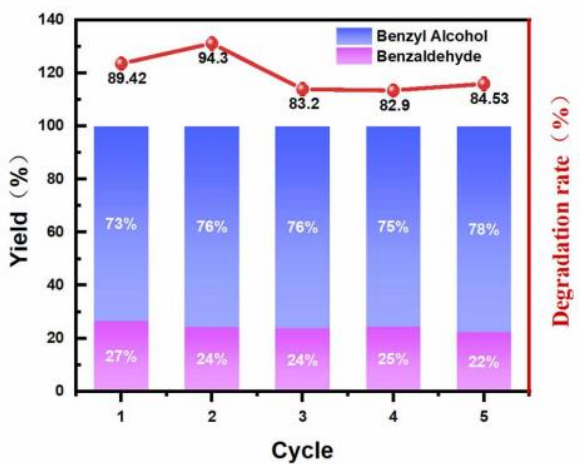

Fig. 5. (a)The setup of a multi-phased continuous reaction system; (b) the yield of main products, benzyl alcohol and benzaldehyde;(c) the calculated degradation efficiency in five consecutive cycles

\section{Products Analysis and Reaction Mechanism}

To clarify the cleavage mechanism of linkage bonds in lignin model compounds, the degradation products were identified by GC-MS. Three kinds of degradation products of PBP were verified as hydroquinone, benzyl alcohol, and benzaldehyde. It could be reasonably deduced that the $\alpha-\mathrm{O}-4$ bond in PBP was cleaved to produce hydroquinone and benzyl alcohol, and part of benzyl alcohol underwent further oxidation to benzaldehyde. Guaiacol was detected in degradation products of GGE, which meant that the $\beta-\mathrm{O}-4$ bond in GGE was cleaved in this reaction system. Based on the above results, the whole mechanism in this reaction system is shown in Fig. 6 (take PBP as an example). Accordingly, $\cdot \mathrm{OH}$ is generated through $\mathrm{H}_{2} \mathrm{O}_{2}$ decomposition catalyzed by solid acid of $\mathrm{SO}_{4}{ }^{2-} / \mathrm{Fe}_{2} \mathrm{O}_{3}-\mathrm{ZrO}_{2}$, and its lifetime is prolonged due to the stabilization effect of ionic liquid. The dissolved lignin model compounds diffuse to the surface of solid acid, then adsorb on the Lewis acid site with $\mathrm{O}$ atom in aryl-alkyl C-O-C bond. After weakening, the ether bond is attacked by $\cdot \mathrm{OH}$, eventually leading to the cleavage of the $\mathrm{C}-\mathrm{O}-\mathrm{C}$ bond. The degradation products rapidly enter into butyl acetate once they were produced, to realize the instant separation of products. 
While the application of this method to actual lignin samples is ongoing, due to the complexity of products analysis, this study promotes the design of the continuous procedure for oxidative degradation of lignin.

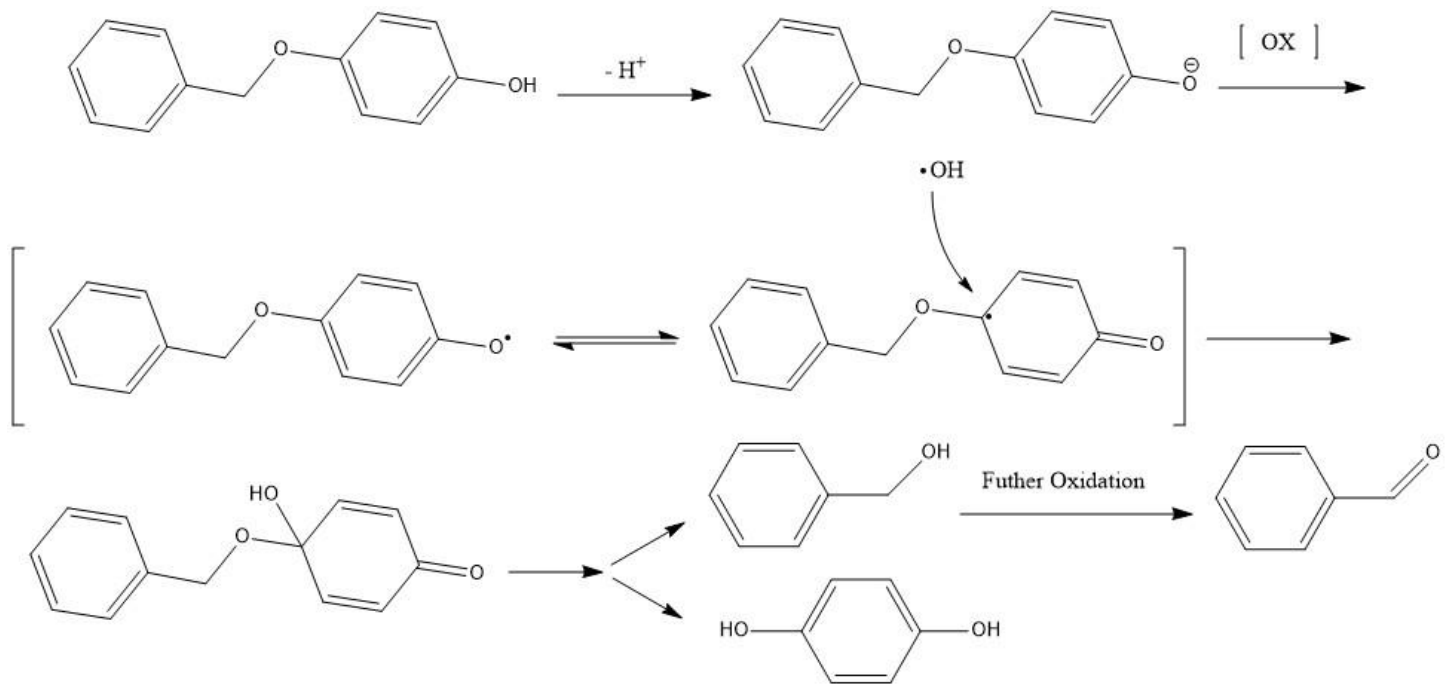

Fig. 6. Scheme of the cleavage of aryl-alkyl ether linkages in lignin model compounds with $\mathrm{H}_{2} \mathrm{O}_{2}$ catalyzed by $\mathrm{SO}_{4}{ }^{2}-/ \mathrm{Fe}_{2} \mathrm{O}_{3}-\mathrm{ZrO}_{2}$

\section{CONCLUSIONS}

1. A reaction system for the selectively oxidative cleavage of lignin model compound was designed, in which the degradation rate achieved more than $95 \%$ for both $\alpha-\mathrm{O}-4$ and $\beta$ O-4 lignin model compounds, under a mild condition with $0.80 \mathrm{~mol} / \mathrm{L} \mathrm{H}_{2} \mathrm{O}_{2}$ and $10 \mathrm{mg}$ $\mathrm{SO}_{4}{ }^{2-} / \mathrm{Fe}_{2} \mathrm{O}_{3}-\mathrm{ZrO}_{2}$ in [BMIM]Cl, reacting at $60{ }^{\circ} \mathrm{C}$ for $2 \mathrm{~h}$.

2. A two-phase continuous reaction system with an average degradation efficiency of $86.9 \%$ was designed, which was also convenient for the recycling of ionic liquid and catalyst.

3. The mechanism of cleavage of aryl-alkyl ether bond was also studied. Lignin model compounds were dissolved in ILs, and the aryl-alkyl ether bond was selectively attacked by $\cdot \mathrm{OH}$ generated through $\mathrm{H}_{2} \mathrm{O}_{2}$ catalyzed decomposition by solid acid $\mathrm{SO}_{4}{ }^{2-}$ $/ \mathrm{Fe}_{2} \mathrm{O}_{3}-\mathrm{ZrO}_{2}$. The degradation rate was improved by the stabilization of $\cdot \mathrm{OH}$ in ionic liquid. The degradation products rapidly entered into butyl acetate once they were produced because of the difference of solubility of the two phases.

\section{ACKNOWLEDGMENTS}

The authors are grateful for the support of Beijing National Science Foundation, No. 2182046. 


\section{REFERENCES CITED}

Amidon, T. E., and Liu, S. (2009). "Water-based woody biorefinery," Biotechnol. Adv. 27(5), 542-550. DOI: 10.1016/j.biotechadv.2009.04.012

Deepa, A. K., and Dhepe, P. L. (2015). "Lignin depolymerization into aromatic monomers over solid acid catalysts," ACS. Catal. 5(1), 365-379. DOI: $10.1021 / \mathrm{cs} 501371 \mathrm{q}$

Fassi, S., Djebbar, K., Bousnoubra, I., Chenini, H., and Sehili, T. (2014). "Oxidation of bromocresol green by different advanced oxidation processes: Fenton, Fenton-like, photo-Fenton, photo-Fenton-like and solar light. Comparative study," Desalin. Water. Treat. 2014(52), 4982-4989. DOI: 10.1080/19443994.2013.809971

Gao, P., Hao, M., He, Y., Song, Y., and Yang, S. (2019). "Effect of $\mathrm{Fe}_{2} \mathrm{O}_{3}-\mathrm{ZrO}_{2}$ catalyst morphology on sulfamethazine degradation in the Fenton-like reaction," Catalysts 9(85), 1-11. DOI:10.3390/catal9010085

Guan, W., Tsang, C.-W., Lin, C. S. K., Len, C., Hu, H., and Liang, C. (2020). "A review on high catalytic efficiency of solid acid catalysts for lignin valorization," Bioresource Technol. 2020(298), 122432. DOI:10.1016/j.biortech.2019.122432

Ismail, M., Rahmani, M. K., Khan, S. A., Choi, J., Hussain,F., Batool, Z., Rana, A. M., Lee, J., Cho, H., and Kim, S. (2019). "Effects of Gibbs free energy difference and oxygen vacancies distribution in a bilayer $\mathrm{ZnO} / \mathrm{ZrO}_{2}$ structure for applications to bipolar resistive switching," Appl. Surf. Sci. 2019(498), 143833. DOI: 10.1016/j.apsusc.2019.143833

Jiang, H. M., Wang, L., Qiao, L., Xue, A., Cheng, Y. J., Chen, Y. Y., Ren, Y., Chen, Y. M., and Wan, P. Y. (2019). "Improved oxidative cleavage of lignin model compound by ORR in protic ionic liquid," Int. J. Electrochem. Sci. 14(3), 2645-2654. DOI: 10.20964/2019.03.10

Kang, Y., Lu, X. M., Zhang, G. J., Yao, X. Q., Xin, J. Y., Yang, S. Q., Yang, Y. Q., Xu, J. L., Feng, M., and Zhang, S. J. (2019). "Metal-free photochemical degradation of lignin-derived aryl ethers and lignin by autologous radicals through ionic liquid induction," ChemSusChem 12(17), 4005-4013. DOI: 10.1002/cssc.201901796

Lei, W., Chen, Y., Liu, S., Jiang, H., and Wan, P. (2017). "Study on the cleavage of alkyl-O-aryl bonds by in situ generated hydroxyl radicals on an ORR cathode," RSC Adv. 7(81), 51419-51425. DOI: $10.1039 / \mathrm{c} 7 \mathrm{ra1} 1236 \mathrm{j}$

Li, C., Zhao, X., Wang, A., Huber, G. W., and Zhang, T. (2015). "Catalytic transformation of lignin for the production of chemicals and fuels," Chem. Rev. 115(21), 11559-11624. DOI: 10.1021/acs.chemrev.5b00155

Li, H., Shang, J., Yang, Z., Shen, W., Ai, Z., and Zhang, L. (2017). “Oxygen vacancy associated surface Fenton chemistry: Surface structure dependent hydroxyl radicals generation and substrate dependent reactivity," Environ. Sci. \& Technol. 51(10), 5685-5694. DOI: $10.1021 /$ acs.est.7b00040

Li, H., and Song, G. (2019). "Ru-catalyzed hydrogenolysis of lignin: Base-dependent tunability of monomeric phenols and mechanistic study," ACS Catal. 9, 4054-4064. DOI: $10.1021 /$ acscatal.9b00556

Persson, H., Han, T., Sandström, L., Xia, W., Evangelopoulos, P., and Yang, W. (2018). "Fractionation of liquid products from pyrolysis of lignocellulosic biomass by stepwise thermal treatment," Energy 2018(154), 346-351. DOI: 10.1016/j.energy.2018.04.150

Prado, R., Brandt, A., Erdocia, X., Hallett, J., and Welton, T. (2016). "Lignin oxidation 
and depolymerisation in ionic liquids," Green Chem. 18(3), 834-841. DOI: $10.1039 / \mathrm{c} 5 \mathrm{gc0} 01950 \mathrm{~h}$

Song, Q., Wang, F., Cai, J., Wang, Y., Zhang, J., Yu, W., and Xu, J. (2013). “Lignin depolymerization (LDP) in alcohol over nickel-based catalysts via a fragmentationhydrogenolysis process," Energ. \& Environ. Sci. 6(3), 994-1007. DOI: $10.1039 / \mathrm{c} 2 \mathrm{ee} 23741 \mathrm{e}$

Tarabanko, V. E., Hendogina, Y. V., Petuhov, D. V., and Pervishina, E. P. (2000). “On the role of retroaldol reaction in the process of lignin oxidation into vanillin. Kinetics of the vanillideneacetone cleavage in alkaline media," React. Kinet. Catal. Lett. 69(2), 361-368. DOI: 10.1023/a:1005620521240

Wang, H. L., Wang, H. M., Kuhn, E., Tucker, M. P., and Yang, B. (2018). "Production of jet fuel-range hydrocarbons from hydrodeoxygenation of lignin over super Lewis acid combined with metal catalysts," ChemSusChem 11(1), 285-291. DOI: 10.1002/cssc.201701567

Xu, C., Arancon, R. A. D., Labidi, J., and Luque, R. (2014). "Lignin depolymerisation strategies: towards valuable chemicals and fuels," Chem. Soc. Rev. 43(22), 74857500. DOI: $10.1039 / \mathrm{c} 4 \mathrm{cs} 00235 \mathrm{k}$

Xu, W., Miller, S. J., Agrawal, P. K., and Jones, C. W. (2012). "Depolymerization and hydrodeoxygenation of switchgrass lignin with formic acid," ChemSusChem 5(4), 667-675. DOI: $10.1002 / \mathrm{cssc} .201100695$

Yang, Q., Wu, S., Lou, R., and Lv, G. (2010). “Analysis of wheat straw lignin by thermogravimetry and pyrolysis-gas chromatography/mass spectrometry," J. Anal. \& Appl. Pyrol. 87(1), 65-69. DOI: 10.1016/j.jaap.2009.10.006

Yuan, Z., Cheng, S., Leitch, M., and Xu, C. C. (2010). "Hydrolytic degradation of alkaline lignin in hot-compressed water and ethanol," Bioresource Technol. 101(23), 9308-9313. DOI: 10.1016/j.biortech.2010.06.140

Yue, Y., Guo, X. X., Liu, T., Liu, H. Y., Wang, T. H., Yuan, P., Zhu, H. B., Bai, Z. S., and Bao, X. J. (2019). "Template free synthesis of hierarchical porous zeolite beta with natural kaolin clay as alumina source,” Micropor. Mesopor. Mater. 2020(293), 109772. DOI: 10.1016/j.micromeso.2019.109772

Zigah, D., Wang, A.-F., Lagrost, C. and Hopiot, P. (2009). "Diffusion of molecules in ionic liquids/organic solvent mixtures. Example of the reversible reduction of $\mathrm{O}_{2}$ to superoxide," J. Phys. Chem. B 113(7), 2019-2023. DOI: 10.1021/jp8095314

Article submitted: April 22, 2020; Peer review completed: June 4, 2020; Revised version received: July 1, 2020; Published: July 8, 2020.

DOI: $10.15376 /$ biores. 15.3.6526-6538 


\section{SUPPLEMENTARY INFORMATION}

\section{Evaluation of Degradation Rate and Product Selectivity HPLC conditions}

The degradation rate of lignin model compounds was analyzed using an Ultimate 3000 HPLC system (Dionex, Sunnyvale, America) equipped with a $\mathrm{C}_{18}$ column $(4.6 \mathrm{~mm}$ i.d.; particle size, $5 \mu \mathrm{m}$; length, $250 \mathrm{~mm}$; Shimadzu) and a UV detector. Under the optimized ratio and flow rate of mobile phase, PBP was analyzed using a mixed solution of methanol and water $(80 \% / 20 \%)$ at $0.5 \mathrm{~mL} / \mathrm{min}, 35^{\circ} \mathrm{C}$. The detection wavelength of UV detector was $235 \mathrm{~nm}$, and $1.0 \mu \mathrm{L}$ sample was injected in to the HPLC system.

GGE was analyzed using a mobile phase with a flow rate of $0.5 \mathrm{~mL} / \mathrm{min}$, gradient elution, the ratio was as follows: $0-3 \mathrm{~min}$ (methanol/ water $=50 \% / 50 \%$ ), 3-16 min (methanol $/$ water $=50 \% / 50 \% \rightarrow$ methanol $/$ water $=80 \% / 20 \%), 16-18 \mathrm{~min}$ (methanol $/$ water $=80 \% / 20 \%), 18-23 \mathrm{~min}$ (methanol/ water $=50 \% / 50 \%$ ). The column temperature was $35^{\circ} \mathrm{C}$. The detection wavelength of $\mathrm{UV}$ detector was $280 \mathrm{~nm}$, and $1.0 \mu \mathrm{L}$ sample was injected.

\section{GC-MS conditions}

GC-MS instrument with electron impact (EI) ion source (QP2010 Ultra, Shimadzu, Japan) was used to analyze the products. Rxi-5Sil MS column (30.0 m x $0.25 \mathrm{~mm}$ i.d. x $0.25 \mu \mathrm{m}$, Restek, USA) was used as an analytical column. Ultra high purity helium was used as the carrier gas at a flow rate of $1.4 \mathrm{~mL} / \mathrm{min}$. The gas chromatograph oven temperature was initially set at $45{ }^{\circ} \mathrm{C}$ for $5 \mathrm{~min}$, then raised to $110{ }^{\circ} \mathrm{C}$ at a rate of $12{ }^{\circ} \mathrm{C}$ / $\mathrm{min}$ and held at this temperature for $1 \mathrm{~min}$, and finally held for $1 \mathrm{~min}$ after raising to 280 ${ }^{\circ} \mathrm{C}$ at a rate of $8{ }^{\circ} \mathrm{C} / \mathrm{min}$ and The injection port temperature was set as $280{ }^{\circ} \mathrm{C}$ with a spilt ration of 20:1. Electron impact (EI) ion source temperature was set at $280^{\circ} \mathrm{C}$, which energy was $70 \mathrm{eV}$. The data was recorded with selected ion monitor (SIM) mode.

\section{Measurement of $\mathrm{H}_{2} \mathrm{O}_{2}$ Concentration}

The concentration of $\mathrm{H}_{2} \mathrm{O}_{2}$ was measured by the $\mathrm{KMnO}_{4}$ titration method. Specifically, approximately $5.0 \mathrm{~g}$ of $\mathrm{KMnO}_{4}$ was dissolved in deionized water $(300.0 \mathrm{~mL})$, namely solution $\mathrm{A}$. Three parts of $\mathrm{Na}_{2} \mathrm{C}_{2} \mathrm{O}_{4}$ of different masses were weighed separately and then dissolved in deionized water $(50.0 \mathrm{~mL})$ together with $\mathrm{H}_{2} \mathrm{SO}_{4}(10.0 \mathrm{~mL}, 1.0 \mathrm{~mol} / \mathrm{L})$ in a water bath at $80^{\circ} \mathrm{C}$ for $30 \mathrm{~min}$. This solution was named solution B. Solution B was used to titrate Solution A to pink and hold for $30 \mathrm{~s}$ without discoloration. This titration experiment was repeated several time for average value. The concentration of solution A is shown by Eq. $\mathrm{S} 1$.

$$
c_{\left(\mathrm{KMnO}_{4}\right)}=2 c_{\left(\mathrm{Na}_{2} \mathrm{C}_{2} \mathrm{O}_{4}\right)} \times v_{\left(\mathrm{Na}_{2} \mathrm{C}_{2} \mathrm{O}_{4}\right)} / 5 v_{\left(\mathrm{KMnO}_{4}\right)}
$$

After calculation, the concentration of solution A was $0.1013 \mathrm{~mol} / \mathrm{L}$.

Then, $320.0 \mu \mathrm{L}$ of $\mathrm{H}_{2} \mathrm{O}_{2}$ (approximately $30 \% \mathrm{v} / \mathrm{w}$ ) was fully mixed into $100.0 \mathrm{~mL}$ of $\mathrm{H}_{2} \mathrm{SO}_{4}(1.0 \mathrm{~mol} / \mathrm{L})$, named solution $\mathrm{C}$. Solution $\mathrm{A}$, which had been known the exact concentration, was used to titrate solution $\mathrm{C}$ in order to calculate the concentration of $\mathrm{H}_{2} \mathrm{O}_{2}$, as shown in Eq. S2.

$c_{\left(\mathrm{H}_{2} \mathrm{O}_{2}\right)}=5 c_{\left(\mathrm{KMnO}_{4}\right)} \times v_{\left(\mathrm{KMnO}_{4}\right)} / 2 v_{\left(\mathrm{H}_{2} \mathrm{O}_{2}\right)}$

After calculation, the actual concentration of the solution $\mathrm{C}$ was $8.78 \mathrm{~mol} / \mathrm{L}$. 
In the contrast experiment, the concentration of $\mathrm{H}_{2} \mathrm{O}_{2}$ droped to $7.49 \mathrm{~mol} / \mathrm{L}$ from $9.02 \mathrm{~mol} / \mathrm{L}$ owing to the catalysis of $\mathrm{SO}_{4}{ }^{2-} / \mathrm{Fe}_{2} \mathrm{O}_{3}-\mathrm{ZrO}_{2}$, while $8.69 \mathrm{~mol} / \mathrm{L}$ without catalysis.

\section{Measurement of $\cdot \mathrm{OH}$}

The concentration of $\cdot \mathrm{OH}$ was measured by the bromocresol green (BG) oxidation method. Specifically, $5.0 \mathrm{~mL}$ of BG in deionized water $\left(1.0 \times 10^{-4} \mathrm{~mol} / \mathrm{L}\right)$ and $5.0 \mathrm{~mL}$ ionic liquid ([BMIM]Cl) were fully mixed. The prepared solution was mixed with $5.0 \mathrm{~mL} \mathrm{NaAc}-$ HAc buffer solution and exactly diluted to $25.0 \mathrm{~mL}$. Then, the UV absorption at $442 \mathrm{~nm}$ was measured. There is a good linear relationship between this UV absorption and the BG concentration, as shown in Fig. S1. Because BG can capture free radicals, the amount of - $\mathrm{OH}$ generated can be measured by the decrease in UV absorption at $442 \mathrm{~nm}$. In the contrast experiment, the concentration of BG droped to $4.02 \times 10^{-5} \mathrm{~mol} / \mathrm{L}$ from $1.0 \times 10^{-4} \mathrm{~mol} / \mathrm{L}$ owing to the catalysis of $\mathrm{SO}_{4}{ }^{2-} / \mathrm{Fe}_{2} \mathrm{O}_{3}-\mathrm{ZrO}_{2}$, while $7.06 \times 10^{-5} \mathrm{~mol} / \mathrm{L}$ without catalyst.

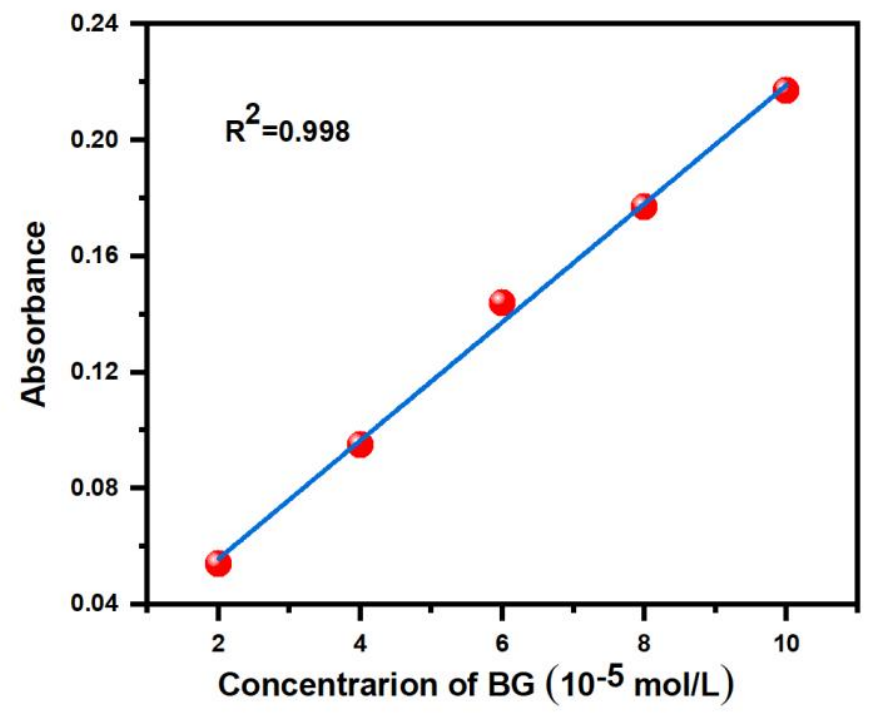

Fig. S1. Standard curve of bromocresol green BG solution 